\title{
Factors Impacting Food Safety Risk Perceptions
}

\section{Glynn T. Tonsor, Ted C. Schroeder and Joost M. E. Pennings}

(Original submitted October 2008, revision received March 2009, accepted April 2009.)

\begin{abstract}
We developed and applied a model of consumer risk perceptions of beef food safety to better understand the underlying drivers of consumer demand for food safety. We show how consumer demographics, country-of-residence, as well as reliance on, and trust in, alternative food safety information sources affect risk perceptions of consumers in Canada, Japan and the United States. Consumers in all three countries have risk perceptions shaped by their level of reliance on observable and credence attribute information. Risk perceptions of consumers in each country are significantly higher for those less trusting of doctors. Moreover, personal and indirect food safety experiences substantially affect risk perceptions. These results are useful to decision-makers in developing more efficient supply chain management strategies and public policies aimed at building or sustaining consumer confidence in food safety.
\end{abstract}

Keywords: Bayesian updating; bivariate Tobit; food safety; information; risk perceptions; trust and reliance.

JEL classifications: $D 12, D 81, D 83, Q 13, Q 18$.

\section{Introduction}

Risk-averse consumers who perceive even very small food safety risks from consuming a product will tend to avoid the product. Events that raise consumer concerns about food safety have resulted in comprehensive and long-lasting closures of

Glynn T. Tonsor is based in the Department of Agricultural, Food, and Resource Economics, Michigan State University. E-mail: gtonsor@msu.edu for correspondence. Ted C. Schroeder is based in the Department of Agricultural Economics, Kansas State University. Joost M. E. Pennings is based in the Department of Agricultural and Consumer Economics, University of Illinois at Urbana-Champaign, and is the AST Professor of Marketing \& Decision Sciences at Wageningen University, The Netherlands. Funding support from the National Beef Industry Development Fund managed by CanFax Research Services is greatly appreciated. We also acknowledge helpful comments from the Editor and two anonymous reviewers. Any errors are the responsibility of the authors. 
specific international markets to particular food products. Understanding what factors drive consumer perceptions and attitudes regarding food safety is essential to designing public policy and industry strategies to effectively deal with food safety events (Kornelis et al., 2007).

Consumer risk perceptions and risk attitudes have been succinctly defined by Schroeder et al. (2007, p. 1):

Risk perceptions represent a person's views about the risk inherent in a particular situation. Perceptions about food safety risk are what the individual believes would be the amount of health risk, if any, they would face from consuming a food product. Risk attitudes are a person's overriding tendencies toward risk across different risky situations. Risk attitudes refer to how willing a person is to accept risk. Risk-averse people place a high premium on ventures that are assured safe, risk-neutral people are indifferent regarding choices with different levels of risk, and risk-seeking individuals pursue risky situations.

The purpose of this study was to determine how specific sources of information and demographics influence consumer perceptions about beef food safety risks. We quantify determinants of risk perceptions of consumers regarding beef food safety in major markets for North American beef including Canada, Japan and the United States. We determine how consumer demographics, country-of-residence and consumer reliance on, and trust in, various information sources affect risk perceptions about food safety.

Several studies have demonstrated the importance of consumer risk attitudes and perceptions regarding food safety on food product demand. Lusk and Coble (2005) found that risk preferences significantly affect consumer preferences for genetically modified food. Mazzocchi et al. (2008) concluded that risk attitudes had a greater impact on poultry purchase decisions than risk perceptions for European (United Kingdom, Italy, Germany, the Netherlands and France) consumers. However, the importance of risk perceptions increased substantially in the event of a salmonella scare. Schroeder et al. (2007) found that risk perceptions and risk attitudes had significant and varied impacts on beef consumption behaviour among consumers in the United States, Canada, Mexico and Japan. For instance, risk perceptions had approximately twice the impact of risk attitudes on consumers who reduced beef consumption in response to food safety concerns in the United States, Canada and Japan.

The literature also includes studies specific to consumer perceptions of bovine spongiform encephalopathy (BSE) risks. Setbon et al. (2005) determined that perceptions of French consumers regarding BSE risk were more related to emotion and value-based judgements than to socio-demographic variables. They also concluded that levels of perceived risk associated with consuming beef during the BSE crisis in France were highly correlated with reduced beef consumption, suggesting that consumers were choosing 'a level of self-protection beyond public measures taken to reduce it' (p. 823). Pennings et al. (2002) found that differences in risk perceptions and attitudes about BSE led to different variations in beef consumption by consumers in the United States, the Netherlands and Germany.

Consumers perceive greater safety hazard about food product attributes with which they are less familiar or where they have no choice about their exposure (Zepeda et al., 2003; Caswell and Joseph, 2006). Furthermore, food safety risk perceptions and attitudes are probably related not only to socioeconomic characteristics, experiences 
and culture but also to trust in various sources of information (Dosman et al., 2001; Lobb et al., 2006, 2007; Mazzocchi et al., 2008).

In formulating perceptions about food safety, consumers may use information from a variety of sources including government, academic researchers, dieticians and physicians. In addition, as food products are labelled in a more detailed manner nowadays, increasingly relevant information is being provided to consumers. As noted by Kornelis et al. (2007), the availability of multiple sources of information does not imply that every consumer equally weights or even uses the same sources. Furthermore, information on product labels is not necessarily relied upon equally by all consumers (Viscusi et al., 1986).

Consumers' risk behaviour is influenced by their trust in risk information and in the providers of this information (Slovic, 1993, 1999; Löfstedt and Frewer, 1998; Cvetkovich and Löfstedt, 1999). The implementation of risk communication programmes often fails because of public distrust in the information source (Löfstedt and Frewer, 1998). Renn and Levine (1991) identified five factors that influence trust: (i) perceived competence of the other party; (ii) the objectivity of the party in providing information; (iii) the degree to which the party takes into account all relevant points of view; (iv) consistency of information; and (v) the 'good will' of the information provider. In the context of food, Frewer et al. (1998) show that whether information is proven to be right or wrong and whether the source is demonstrated to be unbiased determine levels of trust in an information source. Sources that are trusted by the public are seen as knowledgeable and as providing wellresearched information. Trust is more likely to be an important factor in consumer risk behaviour when consumers believe that there are no accurate estimates of the risk available, where Bocker and Hanf (2000) describe trust as being necessary to reduce uncertainty to an acceptable level and simplify one's decisions.

Published research examining diversity in selection, the use of alternative food safety information, and the impact of these on food safety perceptions and attitudes of consumers is limited. Furthermore, examination of drivers shaping consumer risk perceptions and attitudes regarding food safety is sparse. This study contributes to the literature as the first known study to estimate and compare consumer demographics, consumption experiences and reliance on or trust in alternative food safety information in their effects on the risk perceptions of consumers in Canada, Japan and the US. Using both observable (e.g. demographic) and unobservable (e.g. latent food safety trust and reliance) data we illustrate the relative impacts of consumer demographics, country-of-residence, beef consumption experiences and food safety information on consumer beef food safety risk perceptions. Our results can be used to improve efforts to market products to consumers with varying risk attitudes and perceptions, and also to help both industry and policy-makers to influence consumer risk attitudes and perceptions.

\section{Conceptual Framework}

Risk attitude constructs are commonly considered to be rather insensitive to personal experiences and exposure to new information regarding risks (MacCrimmon and Wehrung, 1990; Weber and Milliman, 1997; Weber et al., 2002). In contrast, risk perceptions are often viewed as varying across individuals because of differences in personal experiences and exposure to new information regarding underlying risks (Viscusi, 1989; Liu and Hsieh, 1995; Weber and Milliman, 1997), suggesting 
that risk perceptions are more sensitive to factors such as trust and reliance in food safety information.

Consumers are considered to form subjective probabilities regarding the risk of any event. In this study, riskiness of beef consumption is considered in the context of microbiological hazards. Accordingly, we consider the formation of consumer beef safety risk perceptions in a Bayesian learning framework (Viscusi and O'Connor, 1984; Viscusi, 1989). Let the prior belief of a beef safety risk event be $p$, and let $\gamma$ represent a parameter of the prior distribution of this belief, reflecting the information content underlying this belief. Let $q$ be the latest estimate of the true probability of the beef safety risk event and $\theta$ be the parameter corresponding to the new information content of this updated estimate. The formation of perceived beef safety risk probabilities $(\pi)$ is then given by:

$$
\pi=\frac{\gamma p+\theta q}{\gamma+\theta}
$$

In this framework, individuals use new information to update their prior beliefs. This makes beef safety risk perceptions a weighted-average of prior beliefs and any new risk information.

Following Viscusi (1991), Liu and Hsieh (1995), and Liu et al. (1998) we extend equation (1) to incorporate multiple sources of new information $(q)$. In particular, individuals can obtain beef safety risk information from their own experience of beef consumption $(d b c)$, indirect experiences with food safety (ifs), and publicly available information, denoted for convenience as being from only two sources, $A$ or $B$ (pia and pib). We implement this by decomposing $q$ in equation (1) and rewrite as:

$$
\pi=\frac{\gamma p+\theta_{d b c} d b c+\theta_{i f s} i f_{s}+\theta_{\text {pia }} p i a+\theta_{p i b} p i b}{\gamma+\theta_{d b c}+\theta_{i f s}+\theta_{p i a}+\theta_{p i b}}
$$

where $\theta_{d b c}, \theta_{i f s}, \theta_{\text {pia }}$ and $\theta_{p i b}$ are parameters corresponding to the informational content of direct beef consumption experiences, indirect food safety experiences, public information source $A$, and public information source $B$, respectively. Differentiating equation (2) with respect to $\theta_{\text {pia }}$ yields:

$$
\frac{\partial \pi}{\partial \theta_{p i a}}=\frac{\gamma(p i a-p)+\theta_{d b c}(p i a-d b c)+\theta_{i f s}(p i a-i f s)+\theta_{p i b}(p i a-p i b)}{\left(\gamma+\theta_{d b c}+\theta_{i f s}+\theta_{p i a}+\theta_{p i b}\right)^{2}}>0
$$

if pia $>$ p, pia $>d b c$, pia $>$ ifs and pia $>$ pib.

This result suggests that an increase in the informational content provided publicly from source $A$ will increase an individual's risk perception if this information implies a higher risk (pia) than the individual's prior belief $(p)$, direct experiences $(d b c)$, indirect experiences (ifs) and information from source $B(p i b)$ indicate. We can utilise this formation framework to explain differences in beef safety risk perceptions for individuals of different countries, socioeconomic backgrounds, beef consumption and food safety event experiences, and levels of public information use. 
Equation (2) provides the basis for an empirical model. Prior to formation of this model, it is important to recall the findings of both Schroeder et al. (2007) and Pennings and Smidts (2000) indicating that risk perceptions and attitudes are important drivers of consumer behaviour. Although risk attitudes are believed to be less malleable than perceptions, it is prudent to control for possible endogeneity of risk perceptions and risk attitudes. Unobservable factors (i.e. familiarity with modern food production, cognitive capabilities to accurately process new information) may influence both risk perceptions and attitudes. Failing to recognise this and applying univariate models may produce biased parameter estimates (Doiron and Kalb, 2005; Yoo, 2005; Chang and Robin, 2006). These unobservable patterns are addressed by utilising a bivariate simultaneous equation setting (Cornick et al., 1994). In practice, this ensures that the extent to which unmeasured characteristics of individuals impact both their risk perceptions and attitudes is explicitly taken into account and measured empirically.

We model consumer food safety risk perception and risk attitudes as:

$$
\begin{gathered}
R P_{k}=\delta_{\text {Exp }, k} \mathbf{E x p}_{k}+\delta_{\text {PublicInfo }, k \text { PublicInfo }_{k}+\delta_{\text {Demo }, k \text { Demo }_{k}}} \\
R A_{k}=\lambda_{\text {Demo }, k_{1} \text { Demo }_{k}}
\end{gathered}
$$

where $\operatorname{Exp}_{k}$ and PublicInfo $\boldsymbol{F}_{k}$ are vectors of explanatory variables reflecting personal experiences and publicly available information, respectively, consistent with the framework of equation (2) for consumers residing in country $k$ ( $\forall k=U$ US, Canada and Japan). Demo ${ }_{k}$ is a vector of consumer demographics which is included as they are typically observable, making them frequent targets for potential policy design or niche marketing. $\delta_{j, k}$ and $\lambda_{j, k}(\forall \mathbf{j})$ denote parameter vectors of the model. ${ }^{1} \mathrm{We}$ model risk attitudes solely as a function of demographic variables as studies suggest that risk attitudes are more rigid and less malleable than risk perceptions (MacCrimmon and Wehrung, 1990; Weber and Milliman, 1997; Weber et al., 2002). This, combined with our core focus on risk perceptions as laid out in equations (1)-(3), leads us to the specification of equations (4) and (5).

Equations (4) and (5) provide multiple testable hypotheses regarding drivers of food safety risk attitudes and perceptions. Sample hypotheses include: (i) risk perception and attitude determinants are not country-specific; (ii) risk perceptions are impacted equally by alternative sources of public information; and (iii) risk perceptions are impacted more by direct than indirect experience with beef consumption and food safety events.

\section{Data and Research Methods}

To collect data necessary for this analysis, we conducted an online computer survey of households located in Canada, Japan and the United States, in February and

\footnotetext{
${ }^{1}$ Similar to Liu and Hsieh (1995) and Viscusi (1991), the model is estimated with 'one-period' data in which we have no solid proxy variable for prior beliefs. Hence we assume that the prior belief is expressed in the intercept term of our estimated model and note the value for future research to consider multi-period applications relaxing this restriction (Viscusi and O'Connor, 1984).
} 
March 2006. Online surveys are increasingly being used by marketing and economic researchers, given their comparatively low costs and fast completion times ( $\mathrm{Hu}$ et al., 2006; Louviere et al., 2008; Gao and Schroeder, 2009). Hudson et al. (2004) found that Internet surveys do not exhibit non-response bias. Fleming and Bowden (2009) and Marta-Pedroso et al. (2007) found similar results from applying a webbased survey with a conventional mail and in-person interview survey, respectively. Although these studies support our use of online surveys, we recognise the potential for selection or non-response bias in all survey applications which we are unable to formally evaluate in this analysis.

The survey instrument solicited consumer perceptions and attitudes about beef food safety and determined use of, and trust in, alternative food safety information sources. The surveys were conducted through TNS NFO, a global market research company. TNS NFO has a vast consumer panel worldwide with more than five million individuals in its databank. The target populations were identified by first targeting the primary shopper in each household in the TNS panel. Then, for each household the surveys were distributed based upon Census distributions for household member age, household income, household size, census region and population density stratifications. The general statement used as the subject line to recruit participants in the e-mail survey was the words 'Beef Safety'. The invitation to participate indicated 'You qualify for a survey about beef and poultry products' and provided information regarding survey completion time and number of award points being offered by TNS.

A total of 3,012 respondents completed the survey across all three countries (Canada 1,002; Japan 1,001 and USA 1,009). Summary data of selected demographic attributes of survey respondents are shown in Table 1.

In Canada and Japan, male and female respondents are about equally split, whereas in the United States females represent $83 \%$ of respondents. Most respondents are 35 to 64 years of age, with average age ranging from 42 to 49 years across countries, which is consistent with Census data on age distributions for each of these three countries (US Census Bureau, 2006). A slightly higher proportion of our US and Japanese sample had graduated from college than our Canadian sample.

Respondent income levels (Table 1) were categorised using five-point scales. Income levels of respondents vary within and across country groups, ranging from $49 \%$ of US respondents having income in upper and middle-upper classes $(\$ 60,000$ or greater annual income) to $25 \%$ of Japanese respondents having income in the upper and middle-upper classes (6 million yen or greater annual income).

To be consistent with the conceptual model, we included two survey questions to assess direct and indirect experiences with beef consumption and food safety. In Canada and the United States, approximately 20\% indicated having reduced beef consumption over the last four years because of food safety concerns (Lowered). This is notably lower than the $55 \%$ in Japan indicating a consumption reduction. ${ }^{2}$ We also asked respondents if they or a family member has been sick where the illness was suspected to be caused due to spoiled, tainted or improperly cooked food (Family). Table 1 shows that over one third of our Canadian and United States

\footnotetext{
${ }^{2}$ The four-year period would cover May 2002 to May 2006, encompassing the widely publicised BSE events of December 2003 (McCluskey et al., 2005).
} 
Table 1

Summary statistics of selected demographic variables

\begin{tabular}{|c|c|c|c|}
\hline & Canada & US & Japan \\
\hline \multicolumn{4}{|l|}{ Gender } \\
\hline Female & $52 \%$ & $83 \%$ & $49 \%$ \\
\hline \multicolumn{4}{|l|}{ Age } \\
\hline Average age (years) & 47.7 & 48.9 & 41.8 \\
\hline \multicolumn{4}{|l|}{ College } \\
\hline$=1$ if graduated; 0 otherwise & $24 \%$ & $39 \%$ & $37 \%$ \\
\hline \multicolumn{4}{|l|}{ Income* } \\
\hline I lower & $10 \%$ & $18 \%$ & $33 \%$ \\
\hline II lower-middle & $23 \%$ & $18 \%$ & $21 \%$ \\
\hline III middle & $26 \%$ & $15 \%$ & $21 \%$ \\
\hline IV middle-upper & $19 \%$ & $22 \%$ & $12 \%$ \\
\hline V upper & $22 \%$ & $27 \%$ & $13 \%$ \\
\hline \multicolumn{4}{|c|}{ Lowered beef consumption due to food safety concerns (Lowered) } \\
\hline$=1$ if yes over the last 4 years; 0 otherwise & $20 \%$ & $21 \%$ & $55 \%$ \\
\hline \multicolumn{4}{|c|}{ Family member or self been sick: suspected spoiled or improperly cooked food (Family) } \\
\hline$=1$ if yes; 0 otherwise & $37 \%$ & $36 \%$ & $18 \%$ \\
\hline \multicolumn{4}{|c|}{ Consumer/home food preparer's ability to influence and ensure food safety (CH_Prep) } \\
\hline Very low ability & $2 \%$ & $1 \%$ & $18 \%$ \\
\hline Low ability & $5 \%$ & $4 \%$ & $23 \%$ \\
\hline Moderate ability & $21 \%$ & $23 \%$ & $34 \%$ \\
\hline High ability & $42 \%$ & $43 \%$ & $21 \%$ \\
\hline Very high ability & $29 \%$ & $28 \%$ & $4 \%$ \\
\hline Total respondents & 1,002 & 1,009 & 1,001 \\
\hline
\end{tabular}

Notes: *Canada: I is less than $\$ 15,000$; II $\$ 15,000-\$ 34,999$; III $\$ 35,000-\$ 59,999$; IV $\$ 60,000$ $\$ 79,999 ; \mathrm{V} \$ 80,000$ or more $(\$ C N)$. Japan: I is less than 2.0 ; II 2.0-3.9; III 4.0-5.9; IV 6.07.9; V 8.0 or more (million Japanese Yen). US: I is less than $\$ 22,500$; II $\$ 22,500-\$ 39,999$; III $\$ 40,000-\$ 59,999$; IV $\$ 60,000-\$ 89,999$; V $\$ 90,000$ or more (\$US).

respondents indicated that this indirect illness was applicable to them, compared with only $18 \%$ of our Japanese sample.

A Likert scale question was also included to assess each respondent's perception of the ability to influence and ensure food safety ( $\mathrm{CH}_{-}$Prep). Responses to this question were notably different among Japanese respondents than among Canada or United States respondents. In contrast to only $25 \%$ of Japanese respondents, over $70 \%$ of Canada and United States respondents indicated that they had a high or very high ability. We incorporate this information into the analysis to control for any effects on risk perceptions that may stem from individuals feeling relatively unable to influence the food safety of the environment in which they live. That is, CH_Prep is included to capture effects of perceived self-reliance that may affect risk perceptions.

In addition, each respondent also completed an array of Likert-scale questions which are used to measure risk attitudes and perceptions. An additional sequence of questions was included to determine how consumers obtain, process and put their trust in food safety information from alternative sources. Combined, this unique information set provides a comprehensive assessment of habits and preferences of consumers from three different countries about beef product food safety. 


\subsection{Measuring risk attitudes and risk perceptions}

The two variables of central interest in this study are consumer risk attitudes and perceptions. Consumer food safety risk attitudes and perceptions are unobservable, latent variables. To develop reliable risk attitude and risk perception indices, we used the iterative procedure recommended by Churchill (1979) and Pennings and Smidts (2000). We first generated and included a pool of questions (i.e. indicators) based on the existing literature. Utilising consumer responses to these individual questions (presented in Table 2), confirmatory factor analysis was used to assess the measurement (psychometric) quality of the constructs (Hair et al., 1995; Pennings and Garcia, 2001). ${ }^{3}$

The analytical model underlying the factor analysis assumes that the observed indicators (individual questions in Table 2) are actually generated by latent variables called 'factors' (e.g. risk attitudes and risk perceptions). The relationship between the indicators and the latent variables can be represented by the following matrix equation:

$$
x=\Lambda \kappa+\delta
$$

where $x$ is the $q \times 1$ vector of the $n$ sets of observed variables (i.e. indicators), $\kappa$ is the $n \times 1$ vector of underlying factors (risk attitude and risk perception), $\Lambda$ is the $q \times n$ matrix of regression coefficients relating the indicators to the underlying factors and $\delta$ is the $q \times 1$ vector of error terms of the indicators. A construct is hypothesised to consist of a single factor as we wish to develop unidimensional risk attitude and risk perceptions constructs consistent with the conceptual model (equations 3-5). The overall fit of the model (equation 6) provides all necessary information to assess if a given set of indicators accurately describes risk attitudes and risk perceptions.

All factor loadings [i.e. the regression coefficients, $\Lambda$, in equation (6)] were significant $(P<0.001)$ and greater than 0.4 for all risk attitude and risk perception factor models in each country. ${ }^{4}$ This procedure collectively helps confirm that the observable indicators (e.g. individual questions) load onto the latent constructs (e.g. risk attitude and risk perception indices) in a manner consistent with our specification (Anderson and Gerbing, 1988). Furthermore, this procedure helps ensure that empirical results are not driven by measurement error. Finally, the average sum score of the indicators is used in subsequent analyses to measure risk attitude and risk perception (see Table 3 ).

Larger risk attitude (perception) scale values reflect higher levels of beef food safety risk aversion (perception). Table 3 reveals that Japanese consumers are more

\footnotetext{
${ }^{3} \mathrm{~A}$ reviewer noted that the risk attitude and perception scales may be sensitive to the context in which individual indicator questions were asked. Survey respondents were presented with a set of questions inquiring about their understanding and perceptions regarding microbiological beef food safety hazards. Hence they were probably conditioned with this topic on their minds as they completed the six questions forming our risk attitude and perception indices. As such, we refer to food safety in the context of microbiological hazards (e.g. BSE, Escherichia coli). Alternative assessments with food safety considered in a broader context to include saturated fat/nutrient quality may yield different results.

${ }^{4}$ Full factor analyses can be obtained from the authors.
} 
Table 2

Risk attitude and risk perception individual questions*

\begin{tabular}{|c|c|c|c|}
\hline & \multicolumn{3}{|c|}{ Respondent country } \\
\hline & Canada & US & Japan \\
\hline \multicolumn{4}{|l|}{ Risk attitude statements } \\
\hline $\begin{array}{l}\text { My willingness to accept food safety risk } \\
\text { when eating beef, I am ... ( } 1 \text { = Very Willing, ..., } \\
10=\text { Not at all Willing })\end{array}$ & $4.47^{\mathrm{a}}(2.79)$ & $4.45^{\mathrm{a}}(2.62)$ & $5.70^{\mathrm{b}}(2.06)$ \\
\hline $\begin{array}{l}\text { I rarely think about food safety when eating beef } \\
(1=\text { Strongly Agree, } \ldots, 10=\text { Strongly Disagree })\end{array}$ & $5.05^{\mathrm{a}}(3.08)$ & $4.98^{\mathrm{a}}(2.98)$ & $6.75^{\mathrm{b}}(2.32)$ \\
\hline $\begin{array}{l}\text { For me, eating beef is worth the risk }(1=\text { Strongly } \\
\text { Agree, } \ldots, 10=\text { Strongly Disagree })\end{array}$ & $5.29^{\mathrm{a}}(2.92)$ & $5.00^{\mathrm{b}}(2.75)$ & $7.34^{\mathrm{c}}(2.23)$ \\
\hline \multicolumn{4}{|l|}{ Risk perception statements } \\
\hline $\begin{array}{l}\text { I consider eating beef...( }(1=\text { Not at all Risky, } \ldots, \\
10=\text { Highly Risky })\end{array}$ & $3.38^{\mathrm{a}}(2.31)$ & $3.68^{\mathrm{a}}(2.35)$ & $5.38^{\mathrm{b}}(2.07)$ \\
\hline $\begin{array}{l}\text { When eating beef } \mathrm{I} \text { am exposed to... } \\
(1=\text { No Risk at all, } \\
\ldots, 10=\text { Very High Risk })\end{array}$ & $3.31^{\mathrm{a}}(2.14)$ & $3.64^{\mathrm{b}}(2.22)$ & $5.27^{\mathrm{c}}(2.11)$ \\
\hline $\begin{array}{l}\text { Eating beef is risky }(1=\text { Strongly Disagree, } \\
\ldots, 10=\text { Strongly Agree) }\end{array}$ & $3.34^{\mathrm{a}}(2.31)$ & $3.72^{\mathrm{b}}(2.40)$ & $4.90^{\mathrm{c}}(2.20)$ \\
\hline
\end{tabular}

Notes: *Values presented are averages; standard deviations are reported in parentheses. Mean values sharing the same superscript $(a, b, c)$ are not statistically different $(0.05$ level $)$ from each other.

To examine the measurement quality of the risk attitude and risk perception scales confirmatory factor analysis has been performed (Pennings and Garcia, 2001). The construct reliabilities for risk attitudes are 0.72 for US, 0.56 for Japan and 0.69 for Canada. The reliabilities for risk perceptions are 0.93 for US, 0.92 for Japan and 0.93 for Canada. Discriminate validity scores for Canada, US and Japan are $0.74,0.75$ and 0.69 , respectively, indicating reasonable separation between risk attitude and risk perception scales in all three countries (Campbell and Fiske, 1959).

risk averse regarding beef food safety than Canadian or American consumers. Similarly, Japanese consumers perceive beef to have more food safety risk (highest average risk perception scale of 5.2) than North Americans.

\subsection{Measuring trust and reliance on food safety information sources}

Schroeder et al. (2007) examined the impact of risk aversion and perception on beef consumption. ${ }^{5}$ Consumers trust information from various sources differently (Dosman et al., 2001) and rely on product label information differently (Viscusi et al., 1986). Accordingly, in this analysis we are particularly interested in how consumer reliance and trust in various sources of food safety information affect risk perceptions (equation 4).

\footnotetext{
${ }^{5}$ Interested readers are referred to Schroeder et al. (2007) for a more in-depth discussion of these scales and how they compare across country groups.
} 
Table 3

Risk attitude and risk perception scale distributions

\begin{tabular}{lccc}
\hline & \multicolumn{3}{c}{ Respondent country } \\
\cline { 2 - 4 } Risk attribute & Canada & US & Japan \\
\hline Risk attitude & \multicolumn{3}{c}{ Percentage of respondents } \\
Under 2.5 (Low Risk Aversion) & $36.8 \%$ & $17.3 \%$ & $1.1 \%$ \\
$2.51-5.0$ & $35.1 \%$ & $39.9 \%$ & $16.9 \%$ \\
$5.01-7.5$ & $12.1 \%$ & $30.2 \%$ & $54.7 \%$ \\
Over 7.50 (High Risk Aversion) & 4.9 & $4.5 \%$ & $27.4 \%$ \\
Average Risk Attitude Scale Value & & & 6.6 \\
Risk perception & $45.3 \%$ & $38.9 \%$ & $9.0 \%$ \\
Under 2.5 (Perceive Beef as Safe) & $37.1 \%$ & $37.9 \%$ & $42.1 \%$ \\
2.51-5.0 & $13.1 \%$ & $16.6 \%$ & $36.7 \%$ \\
5.01-7.5 & $4.5 \%$ & $6.7 \%$ & $12.3 \%$ \\
Over 7.50 (Perceive Beef as Unsafe) & 3.3 & 3.7 & 5.2 \\
Average Risk Perception Scale Value & & & \\
\hline
\end{tabular}

Note: Pair-wise chi-square tests reject $(P<0.001)$ the hypotheses of equality in risk attitude and risk perception distributions within each country as well as equality in each index distribution across the four countries.

Lobb et al. (2007) note that devising a single measure of trust in food safety information can be problematic as a measure of consumer reliance on information on products and labels is not advisable. We allow here for multiple measures of both reliance and trust to investigate possibly more subtle impacts on risk perceptions than would be admitted by more aggregate reliance and trust measurements.

We consider consumer use and reliance on information explicitly stated on product labels (e.g. price, governmental inspection, credence attribute claims) as well as information expressed in food products themselves (e.g. colour, texture, smell). Moreover, we consider consumer trust in a range of sources providing information, including health professionals (e.g. physicians and dieticians), experts (e.g. academics, researchers and consumer groups) and entities physically involved in the food supply chain (e.g. grocers, governmental food agencies and industry sources).

Consumer food safety reliance and trust are unobservable, latent constructs. To measure reliance and trust we conducted factor analysis of responses by each consumer to a set of 20 questions measuring food safety information indicators. In particular, the level of trust in alternative sources of food safety information was measured by the following question: 'Listed below are various sources you may look to for providing accurate information on food safety. Please indicate how trustworthy you consider each source'. The answer was captured on a fivepoint Likert scale from 'not at all trustworthy' to 'extremely trustworthy'. Survey participants responded to this trust question for eight possible food safety information sources: (i) Family Physician; (ii) Dietician; (iii) Government Food Agencies; (iv) University Scientists/Educators; (v) Private Researchers/Consultants; (vi) Retail Grocer or Butcher; (vii) Food Industry Sources; and (viii) Consumer Groups. 
The level of reliance on alternative sources of food safety information was similarly measured by the following question: 'When you purchase beef how much do you rely on each of the following sources for accessing food safety information/assurance?', as captured on a five-point Likert scale from 'not at all' to 'extremely'. This question was considered for 12 individual indicators of food safety: (i) Price Level; (ii) Brand Name; (iii) Purchased from Reputable Store; (iv) Country of Origin; (v) Package/Product Date; (vi) Government Inspected; (vii) Labelled Organic; (viii) Labelled Natural; (ix) Product Colour; (x) Product Smell; (xi) Product Texture; and (xii) Labelled Traceable to Farm.

Rather than directly capturing information being used by consumers when they evaluate food safety, our approach was to ask consumers questions about reliance on, and trust in, various information sources. We assume that the higher (lower) the level of trust in a particular information source, the larger (smaller) the influence on food safety risk perceptions and attitudes.

Responses to the 20 reliance and trust questions were factor-analysed using principal component analysis with varimax rotation. This analysis reveals latent factors that appear to drive the processes consumers use in obtaining and interpreting food safety information (i.e. identifies if reliance and trust are unidimensional or not). Based on eigenvalues and factor loadings we selected five factors that (combined), explain over $60 \%$ of the variation and provide a conceptually appealing framework for the individual indicators' (e.g. 20 reliance and trust questions; see Table 4) relationships with each factor. ${ }^{6}$ The five information factors were labelled based on magnitudes of the loading of individual question responses (Table 4). We call the first factor [Factor 1] 'reliance on observable attributes' because observable product attributes of colour, package/product date, texture, smell and price loaded highly on this factor. The second factor [Factor 2] is labelled 'reliance on credence attributes' as beef product credence attributes including organic, natural, traceable, brand name and country of origin loaded highly. Combined, these two factors capture consumer reliance on physical product or product label attributes for forming risk perceptions (Viscusi et al., 1986). The final three factors [Factors 3, 4 and 5] are labelled in similar ways as 'trust in industry, grocer and government', 'trust in researchers and consumer groups' and 'trust in doctors', respectively. These three factors capture trust in three broad information sources, supporting Lobb et al.'s (2007) conclusion that trust should not be analysed with a sole measure. Similar to Boxall and Adamowicz (2002), scores for the five factors were calculated for each respondent and included individually as explanatory variables in the models discussed below.

\subsection{Influences on risk attitudes and perceptions}

Our primary objective is to investigate the relative impacts of consumer demographics, country-of-residence, beef consumption experiences and public information on consumer beef food safety risk perceptions. To do so, we estimate bivariate censored regression (two-limit Tobit) models derived from our theoretical model

\footnotetext{
${ }^{6}$ The addition of factors in excess of the five presented here explains less than $5 \%$ of the variation in our underlying food safety information trust and reliance construct.
} 
Table 4

Factor analysis of statements reflecting trust and reliance in information sources

\begin{tabular}{|c|c|c|c|c|c|}
\hline \multirow[b]{2}{*}{ Information statement } & \multicolumn{5}{|c|}{ Factor loadings } \\
\hline & $\begin{array}{l}\text { Factor 1: } \\
\text { Reliance on } \\
\text { Observable } \\
\text { Attributes }\end{array}$ & $\begin{array}{c}\text { Factor 2: } \\
\text { Reliance } \\
\text { on Credence } \\
\text { Attributes }\end{array}$ & $\begin{array}{l}\text { Factor 3: } \\
\text { Trust in } \\
\text { Industry, } \\
\text { Grocer, \& } \\
\text { Government }\end{array}$ & $\begin{array}{c}\text { Factor 4: } \\
\text { Trust in } \\
\text { Researchers } \\
\text { \& Consumer } \\
\text { Groups }\end{array}$ & $\begin{array}{l}\text { Factor 5: } \\
\text { Trust in } \\
\text { Doctors }\end{array}$ \\
\hline Reliance: Product Colour & 0.83 & 0.03 & 0.05 & 0.03 & 0.05 \\
\hline $\begin{array}{l}\text { Reliance: Package/Product } \\
\text { Date }\end{array}$ & 0.77 & 0.06 & 0.07 & 0.09 & 0.07 \\
\hline Reliance: Product Texture & 0.74 & 0.22 & 0.06 & 0.08 & -0.06 \\
\hline Reliance: Product Smell & 0.70 & 0.10 & 0.02 & 0.04 & 0.16 \\
\hline $\begin{array}{l}\text { Reliance: Purchased from } \\
\text { Reputed Store }\end{array}$ & 0.57 & 0.21 & 0.06 & -0.12 & 0.42 \\
\hline Reliance: Price Level & 0.48 & 0.28 & 0.26 & -0.02 & -0.24 \\
\hline $\begin{array}{l}\text { Reliance: Government } \\
\text { Inspected }\end{array}$ & 0.47 & 0.31 & 0.14 & 0.15 & 0.31 \\
\hline Reliance: Labelled Organic & 0.01 & 0.86 & 0.04 & 0.02 & -0.03 \\
\hline Reliance: Labelled Natural & 0.15 & 0.82 & 0.12 & 0.00 & 0.00 \\
\hline Reliance: Product Traceable & 0.08 & 0.81 & -0.06 & 0.10 & -0.02 \\
\hline Reliance: Brand Name & 0.26 & 0.63 & 0.10 & -0.05 & 0.19 \\
\hline Reliance: Country of Origin & 0.25 & 0.61 & -0.18 & 0.15 & -0.03 \\
\hline Trust: Food Industry Sources & 0.10 & 0.05 & 0.79 & 0.26 & 0.07 \\
\hline $\begin{array}{l}\text { Trust: Retail Grocer or } \\
\text { Butcher }\end{array}$ & 0.10 & 0.01 & 0.73 & 0.00 & 0.32 \\
\hline $\begin{array}{l}\text { Trust: Government Food } \\
\text { Agencies }\end{array}$ & 0.13 & -0.06 & 0.53 & 0.35 & 0.28 \\
\hline Trust: Consumer Groups & 0.06 & 0.11 & 0.05 & 0.77 & 0.11 \\
\hline $\begin{array}{l}\text { Trust: Private Researchers/ } \\
\text { Consultants }\end{array}$ & 0.06 & 0.05 & 0.42 & 0.64 & 0.04 \\
\hline $\begin{array}{l}\text { Trust: University Scientists/ } \\
\text { Educators }\end{array}$ & 0.02 & 0.04 & 0.14 & 0.61 & 0.45 \\
\hline Trust: Family Physician & 0.13 & -0.01 & 0.28 & 0.13 & 0.73 \\
\hline Trust: Dietician & 0.08 & 0.00 & 0.19 & 0.35 & 0.66 \\
\hline Eigenvalues & 5.19 & 2.96 & 1.94 & 0.97 & 0.92 \\
\hline Variance Explained & $25.93 \%$ & $14.81 \%$ & $9.72 \%$ & $4.83 \%$ & $4.59 \%$ \\
\hline
\end{tabular}

(equations 4-5) because the dependent variables (risk attitude and perception scales) are continuous and censored. ${ }^{7}$ We define the two latent variables of core interests $R P_{i}^{*}$ and $R A_{i}^{*}$ such that:

\footnotetext{
${ }^{7}$ Table 2 suggests that these risk attitude and perception scales range from values of 1 to 10 . However, our utilisation of LIMDEP NLOGIT (Greene, 2008) to estimate the presented models required adjusting these scales to range from 0 to 9 . The proportion of limit observations in the Canada, US and Japan samples were $6 \%, 7 \%$, and $4 \%$ for risk attitudes and $17 \%, 13 \%$, and $4 \%$ for risk perceptions, respectively. While we chose to maintain a Tobit specification, results from non-censored regressions (primarily due to partial risk perception censoring) yielded qualitatively similar results.
} 


$$
\begin{aligned}
& R P_{i}^{*}=\mathbf{X}_{\mathrm{RP}, i}^{\prime} \boldsymbol{\beta}_{\mathrm{RP}}+\varepsilon_{\mathrm{RP}, i} \\
& R A_{i}^{*}=\mathbf{X}_{\mathrm{RA}, i}^{\prime} \boldsymbol{\beta}_{\mathrm{RA}}+\varepsilon_{\mathrm{RA}, i}
\end{aligned}
$$

and follow Chang and Robin's (2006) standard formulation of the bivariate by specifying equation (7) as

$$
\begin{aligned}
& R P_{i}= \begin{cases}R P_{i}^{*} & \text { if } 0<R P_{i}^{*}<9 ; \\
0 & \text { if } R P_{i}^{*} \leq 0 ; \\
9 & \text { otherwise }\end{cases} \\
& R A_{i}= \begin{cases}R A_{i}^{*} & \text { if } 0<R A_{i}^{*}<9 ; \\
0 & \text { if } R A_{i}^{*} \leq 0 ; \\
9 & \text { otherwise }\end{cases}
\end{aligned}
$$

In model (7), $\boldsymbol{\beta}$ is a coefficient vector to be estimated, and $\varepsilon_{i} \sim N\left(0, \sigma_{\varepsilon}^{2}\right) . \mathbf{X}_{\mathrm{RP}, i}^{\prime}$ and $\mathbf{X}_{\mathrm{RA}, i}^{\prime}$ are vectors of explanatory variables (including demographics, beef consumption experiences and public information) associated with each individual $i, \boldsymbol{\beta}_{\mathrm{RP}}$ and $\boldsymbol{\beta}_{\mathrm{RA}}$ are corresponding parameter vectors. The error terms, $\varepsilon_{\mathrm{RP}, i}$ and $\varepsilon_{\mathrm{RA}, i}$, are specified following a bivariate normal distribution, with mean 0 , standard deviations of $\sigma_{\mathrm{RP}}$ and $\sigma_{\mathrm{RA}}$, and correlation of $\rho$. Both equations are estimated simultaneously using maximum likelihood procedures in NLOGIT 4.0 (Greene, 2008). By adopting this bivariate model, we are able to test the impact of unobservable factors on both risk perceptions and attitudes. If $\rho$ is zero, use of independent censored regressions would be sufficient (Cornick et al., 1994).

\section{Results}

The model laid out by equation (7) was estimated individually by country, as well as for all multi-country combinations. This facilitated evaluation of our first hypothesis: that risk attitude and perception determinants are not country-specific. We reject the null hypotheses (via likelihood ratio tests) of pooling residents of all three countries, as well as any pair-wise pooling of two individual countries $(P<0.001)$. This suggests that efforts to influence beef risk perceptions and attitudes need to be tailored to the country of residence.

We reject the hypothesis (both by $t$-tests and likelihood ratio tests) of independence between our risk perception and risk attitude regressions as the bivariate model's correlation coefficient is robustly significant in all estimated models. The positive coefficient estimate suggests that unobservable factors omitted from our model (e.g. familiarity with food production and cognitive capabilities to accurately process new information) have the same directional impact on risk perceptions and risk attitudes. Additional likelihood tests led us to reject hypotheses that demographic, beef consumption experience and public information factor variable groups are each jointly insignificant. This suggests that the included covariates jointly have significant impacts on risk attitudes and perceptions. Collectively, we infer that the preferred approach is to use bivariate models estimated individually for each country, including the variables suggested as important in our conceptual model.

Table 5 summarises results from the estimated bivariate Tobit models for each country. In all three models, the majority of the included covariates are each 


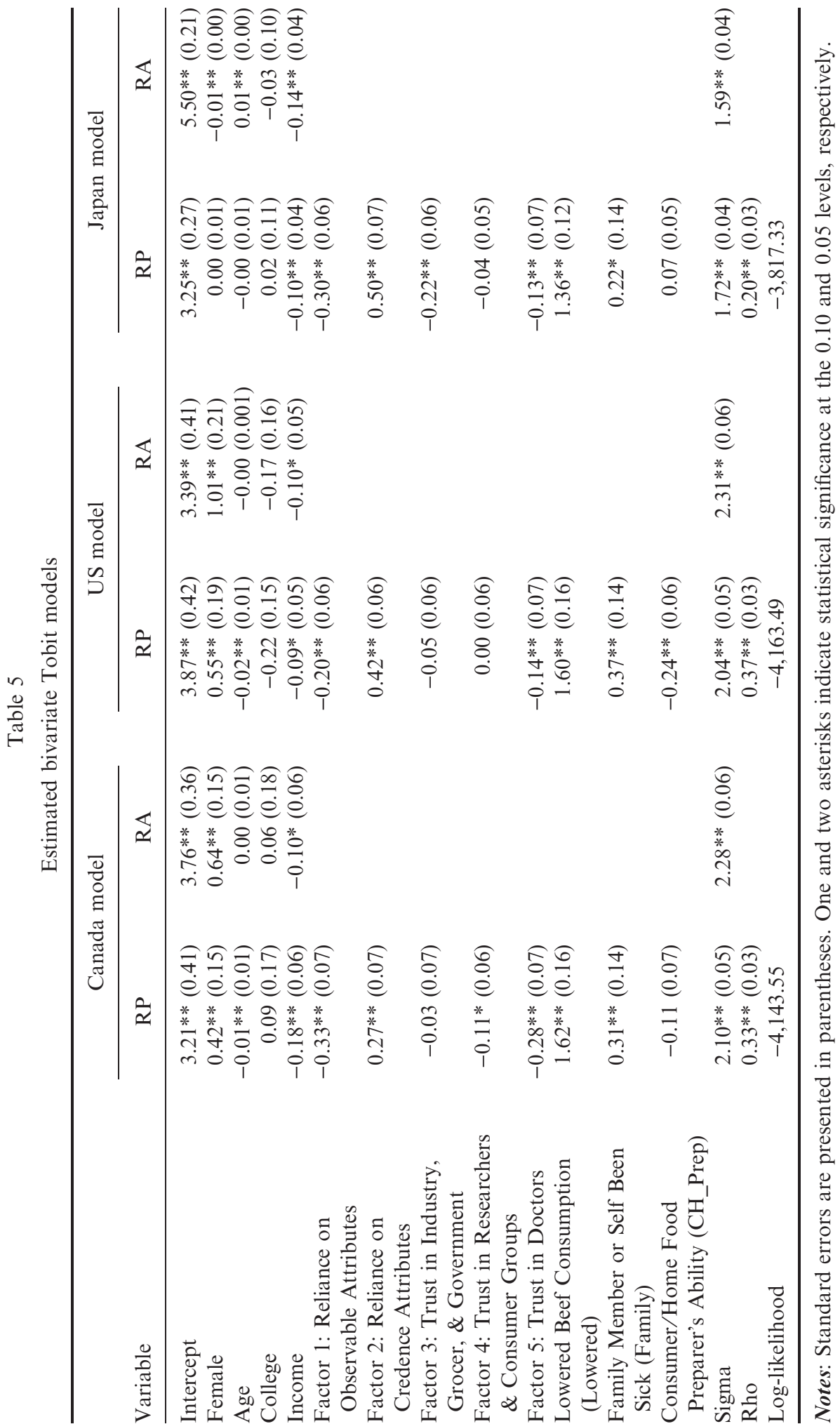


statistically significant. The coefficients in Table 5 are also the marginal effects of included explanatory variables on the risk perception and risk attitude constructs $\left(R P_{i}^{*}\right.$ and $\left.R A_{i}^{*}\right)$ of central interests. ${ }^{8}$ Overall our results are generally consistent with expectations. Regarding observable demographic effects, risk perceptions and attitudes are higher, ceteris paribus, for women in Canada and the US. This is consistent with previous evaluations of gender impacts on risk perceptions (Viscusi, 1991; Liu and Hsieh, 1995). Consumers with higher household incomes have both lower risk perceptions and risk attitudes in all three countries. Perceptions of beef safety risk decrease with age for Canada and US consumers.

Table 5 also shows that risk perceptions are higher for individuals in all three countries who rely more on credence attributes for food safety information [Factor 2]. Moreover, the marginal impact of credence attribute reliance among US and Japanese consumers is notably higher than that of Canadian consumers. Conversely, risk perceptions are lower for individuals, regardless of residence, who rely more on observable attribute information [Factor 1]. The marginal impact of observable attribute reliance is notably lower for US consumers. Our finding of divergent impacts of consumer reliance in observable and credence attributes is noteworthy and provides additional evidence regarding the need to avoid one-dimensional measures of reliance (Viscusi et al., 1986).

Risk perceptions are also lower for individuals in all three countries who place more trust in doctors [Factor 5]. The marginal effect of trust in doctors is notably larger for Canadian consumers. Japanese consumers who place greater trust in industry, grocery stores and government [Factor 3] and Canadian consumers trusting researchers and consumer groups [Factor 4] perceive significantly less food safety risk associated with beef consumption. As with consumer reliance on product information, our identification of diverse impacts of consumer trust in different information sources supports Lobb et al.'s (2007) conclusion that trust should not be considered unidimensional. Moreover, these findings are consistent with the summary provided by Siegrist (2000) of research suggesting that consumer risk perceptions are lower for those trusting experts, government and industry personnel.

Equality in the impact of the five food safety information factors is rejected for all three country groups. In other words, reliance and trust in alternative food safety information sources affect beef safety risk perceptions differently. Our findings of diverse drivers of risk attitudes and risk perceptions are consistent with Kornelis et al. (2007). In particular, different consumers do not utilise the same sources of food safety information and the impacts of alternative information sources vary across consumers.

As expected, individuals in all three countries who have reduced consumption over the past four years due to food safety concerns [Lowered] perceive significantly more risk in beef consumption. Similarly, individuals with indirect food safety experiences, as proxied by a family member having an illness suspected to be food safety-related [Family], perceive higher risk. Interestingly, the marginal effects of direct and personal consumption experience across the three counties are four to six

\footnotetext{
${ }^{8}$ It should be clearly noted that this is not the same as the marginal effects on the observed values of risk perceptions and attitudes $\left(R P_{i}\right.$ and $\left.R A_{i}\right)$ that are more typically evaluated in Tobit models (Greene, 2003). In our context, given the relatively low amount of censoring, these alternative marginal effects approaches are similar.
} 
times larger than the estimated marginal effects of indirect food safety experiences. Significance of both experiences supports the notion that food safety events have spillover effects (i.e. via word of mouth), affecting not only the individual personally experiencing the event but also extending to those in their social network.

Prior to model estimation, we hypothesised that individuals perceiving a higher ability to influence and ensure food safety ( $\mathrm{CH}_{-}$Prep) may perceive less risk consuming beef as they may feel more in control of their food safety environment and personal consequences of consumption. Perhaps surprisingly, this result only holds for US consumers. In particular, Canadian and Japanese respondents' assessments of their own ability to influence and ensure food safety have no significant impact on risk perceptions.

\section{Implications}

As in other evaluations of risk perceptions (e.g., Liu and Hsieh, 1995; Liu et al., 1998), we do not have estimates of the costs associated with effectively influencing consumer reliance and trust levels shown to be important in this analysis. As such, managerial conclusions drawn from this work should compare the marginal benefit of inferences provided here with estimates of marginal costs which need to be evaluated in future studies. Nonetheless, several summary findings can be drawn from this analysis as highlighted in Table 6.

Risk attitudes and perceptions regarding beef food safety are higher for women in Canada and the US and lower for households with higher incomes in all three evaluated countries. As gender and income composition of populations are beyond the influence of beef industry and policy-makers but are generally observable characteristics, these points may be useful in better targeting efforts in product placement or policy design.

Consumers with either direct or indirect experiences with food safety events perceive higher levels of beef safety risk. This supports beef industry investment in

Table 6

Summary of results and implications

\begin{tabular}{ll}
\hline Key findings* & Implications \\
\hline $\begin{array}{l}\text { Risk attitudes and risk perceptions } \\
\text { are related }(\mathrm{C}, \mathrm{J}, \mathrm{U})\end{array}$ & $\begin{array}{c}\text { Researchers need to avoid assumptions } \\
\text { of independence } \\
\text { Attitudes and perceptions differ }\end{array}$ \\
$\begin{array}{c}\text { Gender and income may guide targeting } \\
\text { across gender }(\mathrm{C}, \mathrm{U}) \text { and income }\end{array}$ & products or policies \\
$(\mathrm{C}, \mathrm{J}, \mathrm{U})$ distributions & Multiplier effects exist, increase efforts to \\
$\begin{array}{c}\text { Direct and indirect food safety } \\
\text { experiences impact perceptions }(\mathrm{C}, \mathrm{J}, \mathrm{U})\end{array}$ & reduce event frequency \\
Reliance on credence attributes & Provide accurate, clear information on \\
increases perceptions $(\mathrm{C}, \mathrm{J}, \mathrm{U})$ & credence attributes \\
Reliance on observable attributes & Invest in appealing product presentation \\
reduces perceptions $(\mathrm{C}, \mathrm{J}, \mathrm{U})$ & in retail outlets \\
Trust in doctors reduces & Work closely with health professionals regarding \\
perceptions $(\mathrm{C}, \mathrm{J}, \mathrm{U})$ & food safety education \\
\hline
\end{tabular}

Note: *Letters $\mathrm{C}, \mathrm{J}$ and $\mathrm{U}$ denote the listed key findings that apply to Canada, Japan and United States consumers, respectively. 
efforts aimed at reducing the occurrence of food safety breaches. In particular, the existence of indirect effects suggests that there may be a multiplier effect of food safety events that impacts consumer risk perceptions, and hence beef consumption, going beyond the direct effects suggested by frequency of personal food safety events.

Consumers who rely heavily on credence attribute information for assessing food safety perceive higher levels of beef safety risk. This suggests that industry and government target their efforts to make sure that the messages coming from credence attributes are accurate and readily available to consumers. However, this task may be difficult as credence attribute signals are intentionally conveyed in a variety of ways for marketing purposes that may lead to varied interpretations by consumers. This implies that more attention should be paid not only to the content of these signals but also to the delivery mechanism (e.g. alternative labelling design, advertising).

Consumers who rely on observable product attributes for food safety information perceive lower levels of food safety than those who do not rely on visible cues. This indicates that product presentation at the meat counter affects consumer food safety perceptions. The beef industry may benefit from enhanced efforts to identify these consumer segments to further target their product. Finally, consumers who place considerable trust in information obtained from health professionals perceive low levels of beef safety risk. One implication is that the beef industry should work with health professionals to ensure accurate and reliable safety information.

\section{Discussion and Conclusions}

This study identifies drivers of consumer risk perceptions and attitudes about beef food safety. In particular, we develop and estimate a model accounting for interdependence and censoring in measurement of risk perceptions and attitudes. We quantify how consumer demographics, country-of-residence, consumption experiences and reliance on, and trust in, alternative food safety information sources affect risk perceptions of consumers in Canada, Japan and the United States. Significant heterogeneity across countries is present in how these drivers individually impact consumer food safety risk perceptions. From a managerial perspective this means that governments and industry groups can use the approach to better cope with the heterogeneous responses of consumers towards food safety issues.

Risk perceptions are both higher for Japanese consumers (relative to both United States and Canadian consumers) and for individuals in each country who rely heavily on credence attribute information for food safety signals. In contrast, risk perceptions are lower for individuals that rely on observable attribute information and consumers that put more trust in doctors for beef food safety information. Diverse drivers of risk attitudes and risk perceptions demonstrate that consumers do not utilise the same sources of food safety information and that the impacts of alternative information sources vary across consumers. Moreover, these findings are in line with the conclusions of Viscusi et al. (1987) that '... the nature of individuals' processing of risk information is of considerable consequence ...' (p. 478).

Furthermore, US and Japanese consumer risk perceptions are influenced notably more by their level of reliance on credence attribute information (e.g. organic, natural, traceable and country of origin) than their reliance on observable attribute information (e.g. colour, texture and price) or the trust they place in alternative information sources in assessing food safety. Conversely, risk perceptions of 
consumers in Canada are similarly impacted by reliance on observable or credence information, as well as trust in doctors. The beef industry and government decisionmakers would be well served by targeting their efforts to make sure messages contained in credence attributes are accurate and readily available to consumers. As consumer food safety risk perceptions are strongly related to food product credence attribute information, food labelling regulation needs to ensure labelling integrity. Moreover, the beef industry may benefit from further leveraging consumer trust in doctors and use of observable attributes by continued engagement in efforts aimed at clarity and accuracy of this information to consumers.

While providing a number of valuable contributions, this work also highlights a series of issues worthy of future research. Future work could consider other meat or food categories, as well as consumers in other countries, to examine the sensitivity of our conclusions to food products and consumer groups. Empirical estimation of the costs involved with improving reliance or trust in food safety information are worthy of future effort. The Bayesian model employed in this analysis could be enriched by applying a dynamic panel of observations from consumers allowing a richer evaluation of risk perception updating over time.

\section{References}

Anderson, J. C. and Gerbing, D. W. 'Structural equation modeling in practice: A review and recommended two-step approach', Psychological Bulletin, Vol. 103, (1988) pp. 411-423.

Bocker, A. and Hanf, C. 'Confidence lost and - partially - regained: Consumer response to food scares', Journal of Economic Behavior \& Organization, Vol. 43, (2000) pp. 471-485.

Boxall, P. C. and Adamowicz, W. L. 'Understanding heterogeneous preferences in random utility models: A latent class approach', Environmental and Resource Economics, Vol. 23, (2002) pp. 421-446.

Campbell, D. T. and Fiske, D. W. 'Convergent and discriminant validation by the multitraitmultimethod matrix', Psychological Bulletin, Vol. 56, (1959) pp. 81-105.

Caswell, J. A. and Joseph, S. 'Consumers' food safety, environmental, and animal welfare concerns: Major determinants for agricultural and food trade in the future'. Paper prepared for the IATRC Summer Symposium, Bonn, Germany, May 28-30, 2006.

Chang, C. and Robin, S. 'Doing R\&D and/or importing technologies: The critical importance of firm size in Taiwan's manufacturing industries', Review of Industrial Organization, Vol. 29, (2006) pp. 253-278.

Churchill, G. A. 'A paradigm for developing better measures of marketing constructs', Journal of Marketing Research, Vol. 16, (1979) pp. 64-73.

Cornick, J., Cox, T. L. and Gould, B. W. 'Fluid milk purchases: A multivariate Tobit analysis', American Journal of Agricultural Economics, Vol. 76, (1994) pp. 74-82.

Cvetkovich, G. and Löfstedt, R. 'Introduction: Social trust in risk management', in G. Cvetkovich and R. Lofstedt (eds.), Social Trust and the Management of Trust, 1st edn. (London: Earthscan Publications Ltd, 1999, pp. 1-8).

Doiron, D. and Kalb, G. 'Demands for child care and household labour supply in Australia', The Economic Record, Vol. 81, (2005) pp. 215-236.

Dosman, D. M., Adamowicz, W. L. and Hrudey, S. E. 'Socioeconomic determinants of health- and food safety-related risk perceptions', Risk Analysis, Vol. 21, (2001) pp. 307317.

Fleming, C. M. and Bowden, M. 'Web-based surveys as an alternative to traditional mail methods', Journal of Environmental Management, Vol. 90, (2009) pp. 284-292.

Frewer, L. J., Howard, C., Hedderley, D. and Shepherd, R. 'What determines trust in information about food-related risks? Underlying psychological constructs', in R. Löfstedt and 
L. Frewer (eds.), Risk \& Modern Society, 1st edn. (London: Earthscan Publications Ltd, 1998, pp. 193-212).

Gao, Z. and Schroeder, T. C. 'Effects of label information on consumer willingness-to-pay for food attributes', American Journal of Agricultural Economics, forthcoming.

Greene, W. H. Econometric Analysis, 4th edn. (Upper Saddle River, NJ: Prentice Hall, 2003).

Greene, W. H. NLOGIT Version 4.0 Reference Guide (Plainview, NY: Econometric Software, Inc, 2008).

Hair, J. F., Anderson, R. E., Tanham, R. L. and Black, W. C. Multivariate Data Analysis (Englewood Cliffs, NJ: Prentice Hall, Inc, 1995).

Hu, W., Veeman, M. M. and Adamowicz, W. L. 'Labelling genetically modified food: Heterogeneous consumer preferences and the value of information', Canadian Journal of Agricultural Economics, Vol. 53, (2005) pp. 83-102.

Hudson, D., Seah, L., Hite, D. and Haab, T. 'Telephone presurveys, self-selection, and non-response bias to mail and Internet surveys in economic research', Applied Economics Letters, Vol. 11, (2004) pp. 237-240.

Kornelis, M., Jonge, J., Frewer, L. and Dagevos, H. 'Consumer selection of food-safety information sources', Risk Analysis, Vol. 27, (2007) pp. 327-335.

Liu, J. and Hsieh, C. 'Risk perception and smoking behavior: Empirical evidence from Taiwan', Journal of Risk and Uncertainty, Vol. 11, (1995) pp. 139-157.

Liu, J., Huang, J. and Brown, G. L. 'Information and risk perception: A dynamic adjustment process', Risk Analysis, Vol. 18, (1998) pp. 689-699.

Lobb, A. E., Mazzocchi, M. and Traill, W. B. 'Risk perception and chicken consumption in the avian flu age - A consumer behaviour study on food safety information'. Selected paper presented at the American Agricultural Economics Annual Meeting, Long Beach, CA, 23-26 July, 2006.

Lobb, A. E., Mazzocchi, M. and Traill, W. B. 'Modelling risk perception and trust in food safety information with the theory of planned behaviour', Food Quality and Preference, Vol. 18, (2007) pp. 384-95.

Löfstedt, R. and Frewer, L. 'Introduction', in R. Lofstedt and L. Frewer (eds.), Risk \& Modern Society, 1st edn. (London: Earthscan Publications Ltd, 1998, pp. 3-27).

Louviere, J. J., Islam, T., Wasi, N., Street, D. and Burgess, L. 'Designing discrete choice experiments: Do optimal designs come at a price?' Journal of Consumer Research, Vol. 35, (2008) pp. 360-375.

Lusk, J. L. and Coble, K. H. 'Risk perceptions, risk preference, and acceptance of risky food', American Journal of Agricultural Economics, Vol. 87, (2005) pp. 393-405.

MacCrimmon, K. R. and Wehrung, D. A. 'Characteristics of risk taking executives', Management Science, Vol. 36, (1990) pp. 422-435.

Marta-Pedroso, C., Freitas, H. and Domingos, T. 'Testing for the survey mode effect on contingent valuation data quality: A case study of web based versus in-person interviews', Ecological Economics, Vol. 62, (2007) pp. 388-398.

Mazzocchi, M., Lobb, A., Traill, W. B. and Cavicchi, A. 'Food scares and trust: A European study', Journal of Agricultural Economics, Vol. 59, (2008) pp. 2-24.

McCluskey, J. J., Grimsrud, K. M., Ouchi, H. and Wahl, T. I. 'Bovine spongiform encephalopathy in Japan: Consumers' food safety perceptions and willingness to pay for tested beef', Australian Journal of Agricultural and Resource Economics, Vol. 49, (2005) pp. 197209.

Pennings, J. M. E. and Garcia, P. 'Measuring producers' risk preferences: A global risk attitude construct', American Journal of Agricultural Economics, Vol. 83, (2001) pp. 993-1009.

Pennings, J. M. E. and Smidts, A. 'Assessing the construct validity of risk attitude', Management Science, Vol. 46, (2000) pp. 1337-1348.

Pennings, J. M. E., Wansink, B. and Meulenberg, M. T. G. 'A note on modeling consumer reactions to a crisis: The case of the mad cow disease', International Journal of Research in Marketing, Vol. 19, (2002) pp. 91-100. 
Renn, O. and Levine, D. 'Credibility and trust in risk communication', in R. E. Kasperson and P. J. M. Stallen (eds.), Communicating Risks to the Public, 4th edn. (The Hague: Kluwer, 1991, pp. 175-218).

Schroeder, T. C., Tonsor, G. T., Pennings, J. M. E. and Mintert, J. 'Consumer food safety risk perceptions and attitudes: Impacts on beef consumption across countries', The B.E. Journal of Economic Analysis \& Policy, Vol. 7, 2007 (Contributions): Article 65.

Setbon, M., Raude, J., Fischler, C. and Flahault, A. 'Risk perception of the "mad cow disease" in France: Determinants and consequences', Risk Analysis, Vol. 25, (2005) pp. 813826.

Siegrist, M. 'The influence of trust and perceptions of risks and benefits on the acceptance of gene technology', Risk Analysis, Vol. 20, (2000) pp. 195-203.

Slovic, P. 'Perceived risk, trust and democracy', Risk Analysis, Vol. 13, (1993) pp. 675-682.

Slovic, P. 'Trust, emotion, sex, politics, and science: Surveying the risk-assessment battlefield', Risk Analysis, Vol. 19, (1999) pp. 689-701.

US Census Bureau. 'International database summary demographic data'. Available at: http:// www.census.gov/ipc/www/idbsum.html. Accessed June, 2006.

Viscusi, W. K. 'Prospective reference theory: Toward an explanation of the paradoxes', Journal of Risk and Uncertainty, Vol. 2, (1989) pp. 235-263.

Viscusi, W. K. 'Age variations in risk perceptions and smoking decisions', Review of Economics and Statistics, Vol. 73, (1991) pp. 577-588.

Viscusi, W. K. and O'Connor, C. 'Adaptive responses to chemical labeling: Are workers Bayesian decision makers?' American Economic Review, Vol. 74, (1984) pp. 942-956.

Viscusi, W. K., Magat, W. A. and Huber, J. 'Informational regulation of consumer health risks: An empirical evaluation of hazard warnings', RAND Journal of Economics, Vol. 17, (1986) pp. 351-365.

Viscusi, W. K., Magat, W. A. and Huber, J. 'An investigation of the rationality of consumer valuations of multiple health risks', RAND Journal of Economics, Vol. 18, (1987) pp. 465479.

Weber, E. U. and Milliman, R. A. 'Perceived risk attitudes: Relating risk perception to risky choice', Management Science, Vol. 43, (1997) pp. 123-144.

Weber, E. U., Blais, A. and Betz, N. E. 'A domain-specific risk-attitude scale: Measuring risk perceptions and risk behaviors', Journal of Behavioral Decision Making, Vol. 15, (2002) pp. 263-290.

Yoo, S. 'Analysing household bottled water and water purifier expenditures: Simultaneous equation bivariate Tobit model', Applied Economics Letters, Vol. 12, (2005) pp. 297-301.

Zepeda, L., Douthitt, R. and You, S.-Y. 'Consumer risk perceptions toward agricultural biotechnology, and self-protection, and food demand: The case of milk in the United States', Risk Analysis, Vol. 23, (2003) pp. 973-984. 